\title{
Lidil
}

Revue de linguistique et de didactique des langues

$57 \mid 2018$

Démarches créatives, détours artistiques et appropriation des langues

\section{Enjeux : revue de formation continuée et de didactique du français, $\mathrm{n}^{\circ} 90$ \\ printemps-été 2016, Presses universitaires de Namur}

\section{Edna Sánchez}

\section{OpenEdition \\ Journals}

Édition électronique

URL : http://journals.openedition.org/lidil/4845

DOI : 10.4000/lidil.4845

ISSN : $1960-6052$

Éditeur

UGA Éditions/Université Grenoble Alpes

Édition imprimée

ISBN : 978-2-37747-048-8

ISSN : $1146-6480$

Référence électronique

Edna Sánchez, "Enjeux : revue de formation continuée et de didactique du français, n॰ 90 », Lidil [En ligne], 57 | 2018, mis en ligne le 01 mai 2018, consulté le 24 septembre 2020. URL : http:// journals.openedition.org/lidil/4845; DOI : https://doi.org/10.4000/lidil.4845

Ce document a été généré automatiquement le 24 septembre 2020

(C) Lidil 


\section{Enjeux : revue de formation continuée et de didactique du français, $\mathrm{n}^{\circ} 90$}

printemps-été 2016, Presses universitaires de Namur

Edna Sánchez

\section{RÉFÉRENCE}

Enjeux : revue de formation continuée et de didactique du français, $n^{\circ}$ 90, printemps-été 2016, Presses universitaires de Namur

1 Dans le numéro 90 de la revue Enjeux, les auteurs des cinq contributions offrent des pistes de réflexion sur différents objets d'enseignement: l'oral, la dictée, la francisation, le surréalisme et la lecture. Les contributions dépassent les états de lieux pour fournir au public tant des modèles de formation que des questionnements pour la recherche.

2 L'enseignement scolaire est le contexte pour aborder l'oral, la dictée et la lecture dans la publication. Ainsi, "L'atelier formatif: un modèle pour enseigner l'oral», de Christian Dumais et Geneviève Messier, présente un modèle didactique qui considère l'oral comme un objet d'enseignement-apprentissage à part entière, lié fortement à la pratique chez les élèves. Se basant sur une séquence didactique de Dolz et Schneuwly, le modèle d'atelier formatif est composé de six étapes. Déjà mis en pratique, il s'avère adaptable à plusieurs autres environnements d'enseignement : université, secondaire et primaire. Les auteurs s'interrogent sur le public qui pourrait être le plus concerné par ce modèle et les incidences de celui-ci dans différents contextes.

3 La dictée est le sujet d'Hervé Hunkeler dans « Approche diachronique des pratiques et représentations de la dictée au collège ». L'auteur y expose les résultats d'une recherche sur l'évolution des pratiques et des représentations de cet exercice chez des enseignants de collège. Un parcours de la dictée dans l'histoire des programmes scolaires et son impact dans les familles françaises est présenté dans un premier temps, qui débouche sur son lien étroit à la littérature, aux problèmes de notation et 
questionne le but de cet exercice dans les domaines de l'apprentissage et de l'évaluation. La deuxième partie de l'article est consacrée aux résultats de la recherche qui montrent, entre autres, que l'exercice est toujours présent mais moins pratiqué actuellement et que sa notation en est un point critique.

La réflexion sur la lecture est abordée par Micheline Dispy et Jean-Louis Dumortier dans « Des dispositifs didactiques pour développer des compétences de lecture dans l'enseignement primaire en exploitant les livres de jeunesse ». L'article s'adresse aux maitres du primaire pour les aider à clarifier les expressions telles que "dispositifs didactiques ", " compétences de lecture ", "livres de jeunesse ", et aboutir à quatre recommandations concernant les buts à atteindre, les supports à choisir, les tâches à effectuer et le choix de l'évaluation. L'orientation de l'article offre des éclairages sur les lacunes dans la formation des maitres concernant la lecture et ses pratiques. La contribution établit des bases théoriques pour ensuite interroger son enseignement effectif.

5 Une contribution sur le français langue seconde de André Yaba, Olivier Dezutter et France Lacourse («La première francisation des immigrants adultes au Québec : clef de l'intégration sociale ou barrière pour l'insertion professionnelle?») offre une vision intéressante sur les problématiques de la formation en français pour des immigrants adultes au Québec. Après une brève contextualisation, les auteurs expliquent pourquoi, pour eux, cette formation n'assure pas une insertion professionnelle idéale, car elle ne permet pas l'intégration sociale et économique des immigrants allophones adultes, du fait du manque d'enseignement des compétences scripturales en FRL2.

Finalement, la littérature comme objet d'enseignement est abordée par Nathalie Gillain dans «Le cinéma d'avant-garde au pied de la lettre. Enseigner le Surréalisme et le Nouveau Roman en s'appuyant sur l'analyse de séquences cinématographiques ». Par l'analyse de plusieurs films du surréalisme, dont Un chien andalou (Luis Buñuel et Salvador Dali) et L'année dernière à Marienbad (Alain Resnais), l'auteure offre un éventail d'éléments permettant de repenser l'enseignement de la littérature à partir d'analyses de films. Elle montre comment les séquences cinématographiques permettent d'enseigner les procédés narratifs des surréalistes et les nouveaux romanciers. L'article est riche en descriptions et interprétations, utiles pour comprendre aussi bien le mouvement artistique que les moyens pour l'enseigner.

7 Le parcours de lecture offert par ce numéro de la revue Enjeux est fécond pour les enseignants et futurs enseignants du français LM, LS et LE. En élargissant le public grâce à son langage clair et simple, le numéro aboutit à piquer la curiosité des lecteurs, les invite à lire l'ensemble des contributions et à trouver ainsi des éléments pour améliorer les pratiques enseignantes et découvrir, pourquoi pas, des pistes de recherche-action. 


\section{AUTEUR}

EDNA SÁNCHEZ

LIDILEM, Université Grenoble Alpes 